\title{
Topographic
}

Maps

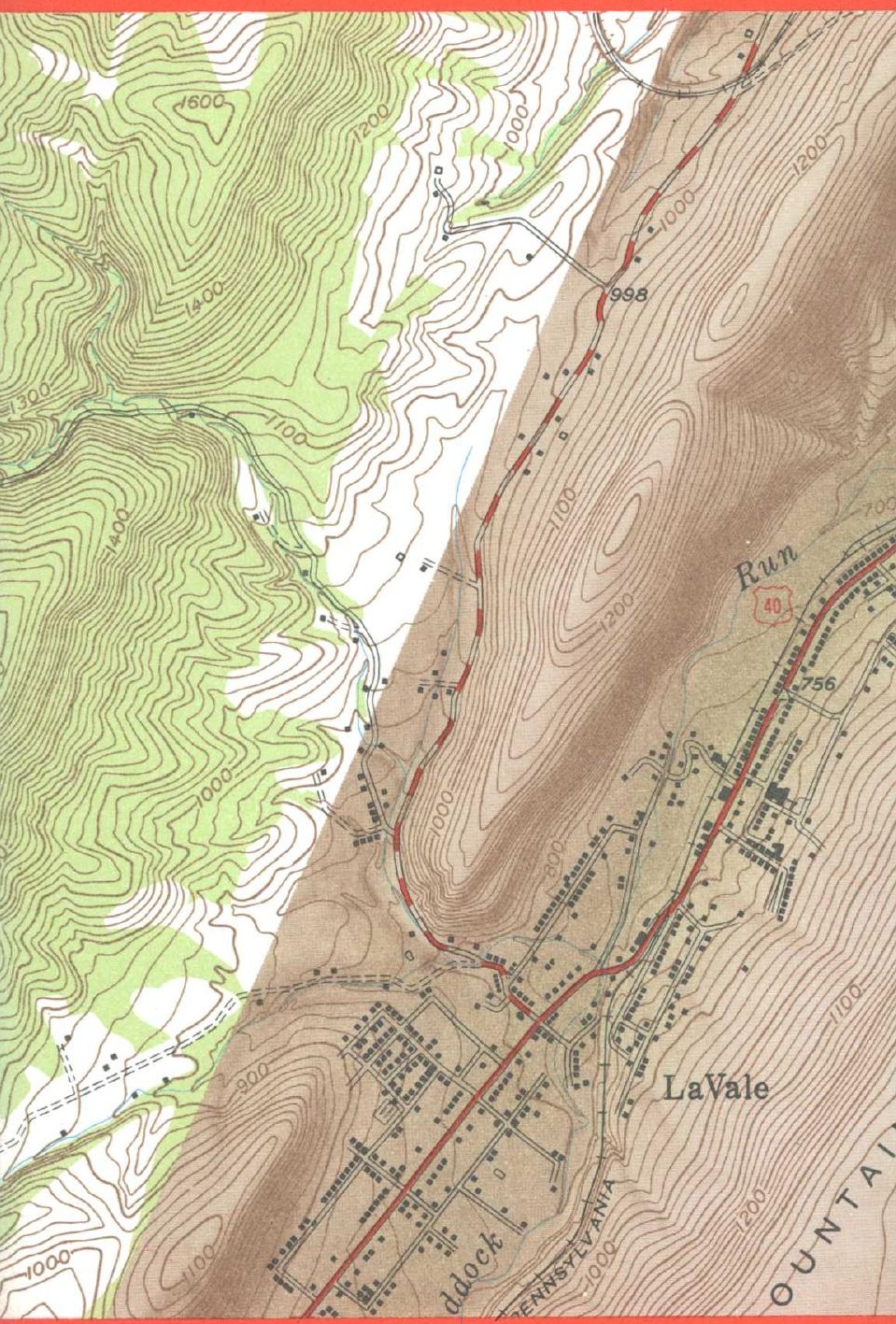

United States Department of the Interior/Geological Survey 


\section{Topographic Maps}

by Theodore D. Steger

\section{What is a Topographic Map?}

A topographic map is a line-and-symbol representation of natural and selected man-made features of a part of the Earth's surface plotted to a definite scale. A distinguishing characteristic of a topographic map is the portrayal of the shape and elevation of the terrain by contour lines.

The physical and cultural characteristics of the terrain, as determined by precise engineering surveys and field inspection, are recorded on the map in a convenient, readable form. Topographic maps show the location and shape of mountains, valleys, and plains ; the networks of streams and rivers; and the principal works of man. 

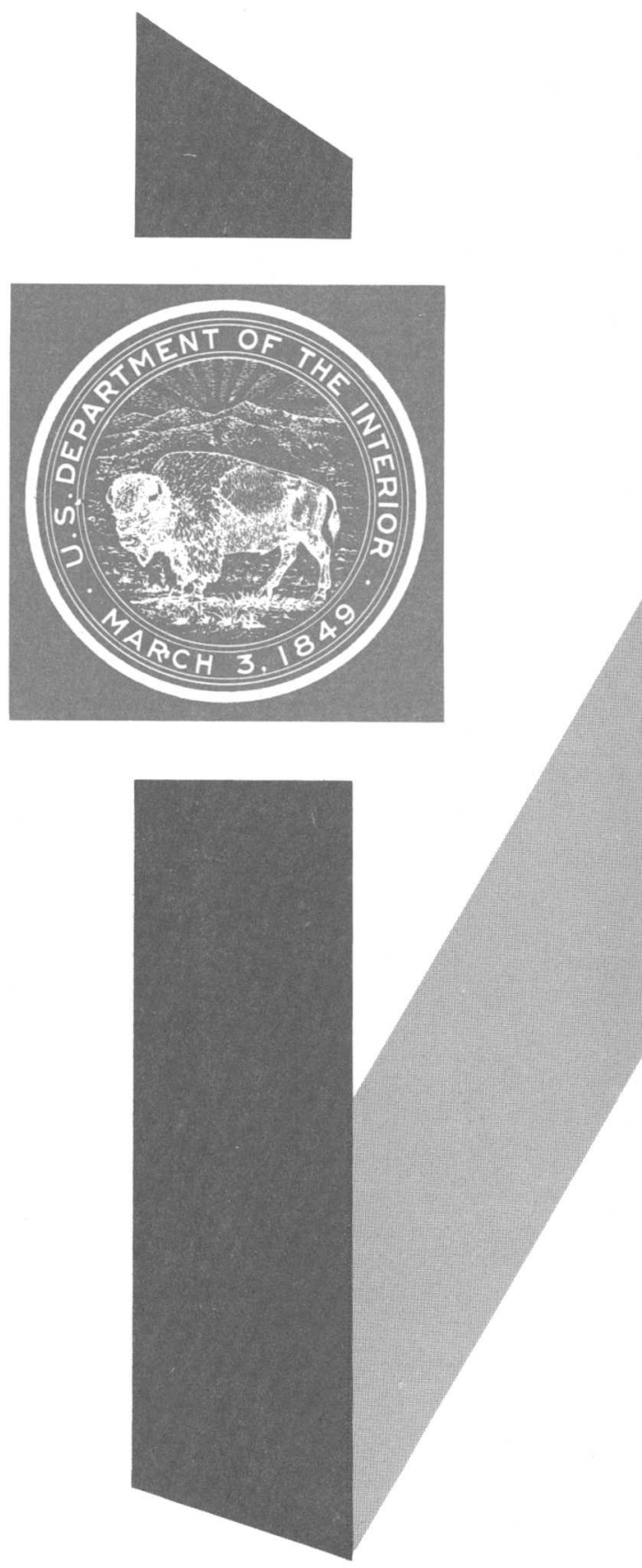

מU.S. GOVERNMENT PRINTING OFFICE: 1978 0--274-961

For sale by the Superintendent of Documents

U.S. Government Printing Office, Washington, D.C. 20402

Stock Number 024-001-02793-3 


\section{THE UNITED STATES GEOLOGICAL SURVEY}

THE UNITED STATES GEOLOGICAL SURVEY was established by Congress in 1879 to consolidate four earlier organizations that had been engaged in topographic and geologic mapping and in collecting information about the public lands. From the beginning of this work, it was evident that adequate classification of lands and conclusive geologic determinations depended on suitable base maps. A general plan was adopted in 1882 for the production of a series of topographic maps at three scales. Under this plan each map covers an area bounded by meridians of longitude and parallels of latitude and is called a quadrangle map.

The plan of 1882 has been expanded and modified over the years to meet the needs of a growing Nation and to satisfy numerous civil and military needs not contemplated in the 1879 Act. A principal objective of the Geological Survey's National Mapping Program is to provide multipurpose maps and related data of appropriate scale, content, and accuracy to satisfy modern requirements. A major element of this program is the series of topographic maps produced by the Geological Survey. 


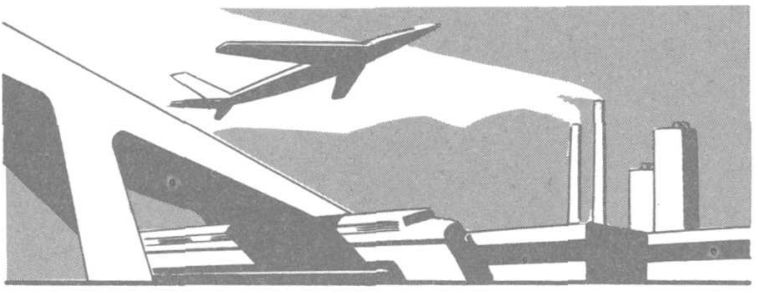

TOPOGRAPHIC MAPS have many uses as basic tools for planning and executing projects that are necessary to our way of life. They are of prime importance in planning airports, highways, dams, pipelines, transmission lines, industrial plants, and countless other types of construction. They are an essential part of ecological studies and environmental control, geologic research, studies of the quantity and quality of water, and projects for flood control, soil conservation, and reforestation. Intelligent and efficient development of our natural resources depends on the availability of adequate topographic maps.

In addition, the growing list of map users includes many who have discovered the advantages of topographic maps in outdoor activities such as hunting, fishing, and vacationing. Reliable maps showing relief features, wooded areas and clearings, and watercourses are of inestimable value to the hiker. In fact, all of the outdoors can be better understood and appreciated with the aid of topographic maps.

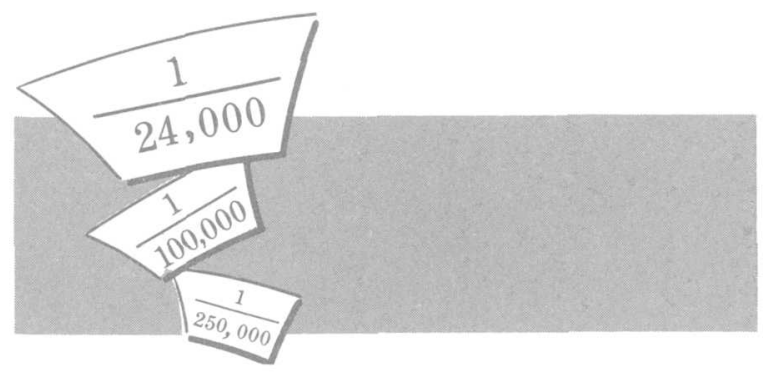

MAP SCALE defines the relationship between the measurements of the features as shown on the map and as they exist on the Earth's surface. Scale is generally stated as a ratio or fraction- 
$1: 24,000$ or $1 / 24,000$. The numerator, customarily 1 , represents map distance, and the denominator, a large number, represents horizontal ground distance. Thus the scale 1:24,000 states that any unit, such as 1 inch or 1 centimeter on the map represents 24,000 of the same unit on the ground.

Maps are classified generally by publication scale, and each scale series fulfills a range of map needs. The illustrations show the contrast between maps of large, intermediate, and small scale.

Large-scale maps, such as 1:24,000, are especially useful for highly developed areas or rural areas where detailed information is needed for engineering planning or similar purposes.

Intermediate-scale maps, ranging from $1: 50,000$ to $1: 100,000$, cover larger areas and are especially suited for land management and planning.

Small-scale maps, 1:250,000, 1:500,000, and $1: 1,000,000$, cover very large areas on a single sheet and are useful for comprehensive views of extensive projects or for regional planning.

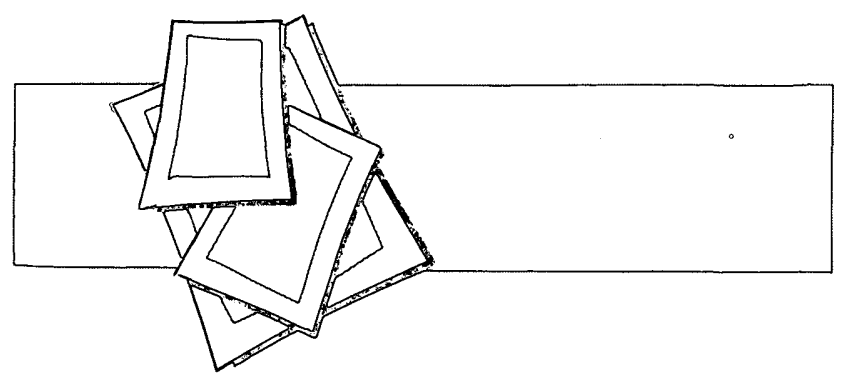

THE TOPOGRAPHIC MAP SERIES of the National Mapping Program includes quadrangle and other map series published by the Geological Survey. A map series is a family of maps conforming generally to the same specifications or having some common unifying characteristic such as scale. Adjacent maps of the same quadrangle series can generally be combined to form a single large map.

The principal map series and their essential characteristics are given in the following table. 


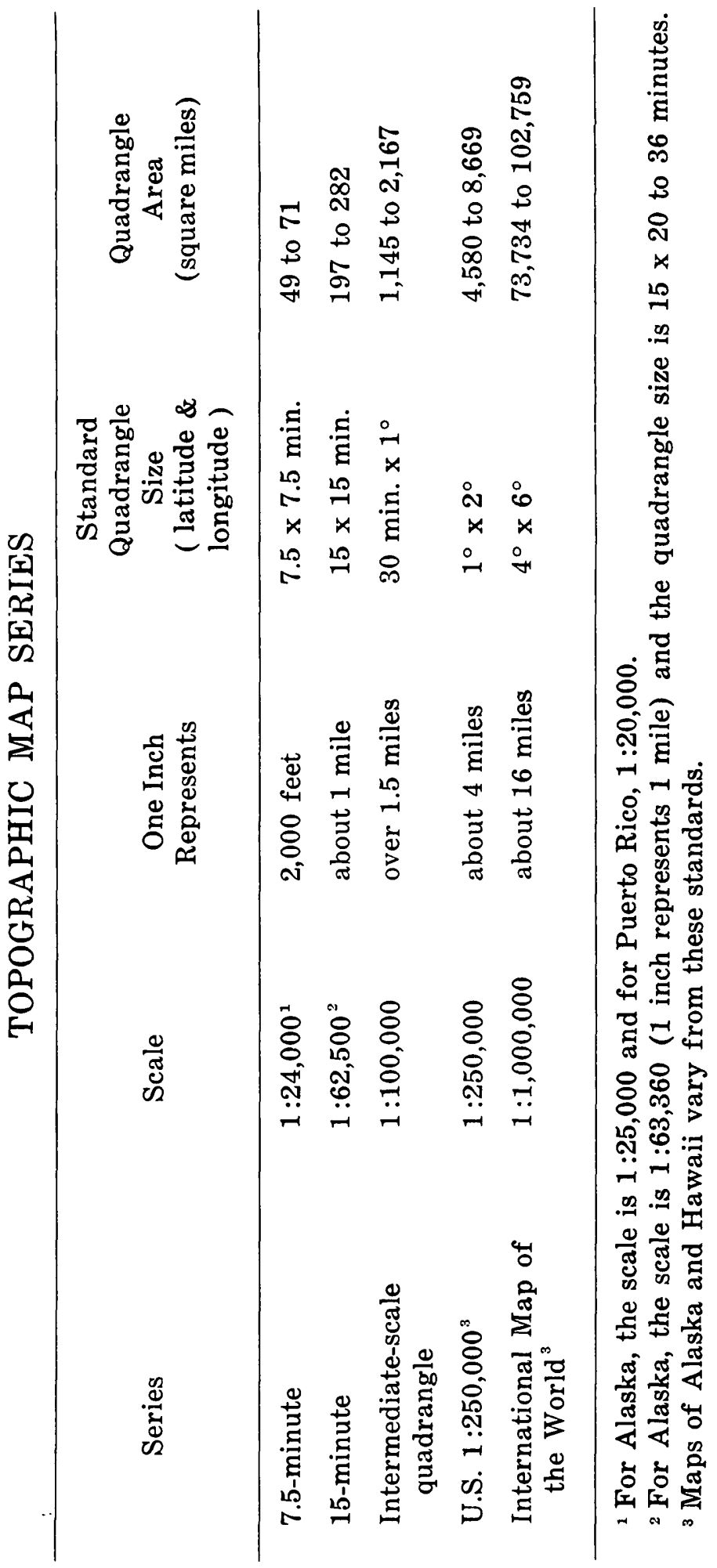


The National Mapping Program also includes other special purpose maps and related map data. These include:

Orthophotomaps, produced for selected quadrangles in the Topographic Map Series, show land features primarily by color-enhanced photographic images which have been processed to show detail in true position. Orthophotomaps may or may not include contours. Because imagery naturally depicts an area in a more true-tolife manner than the conventional line map, the orthophotomap provides an excellent portrayal of extensive areas of sand, marsh, or flat agricultural areas.

Orthophotoquads are a basic type of photoimage map prepared in quadrangle map format. They can be produced quickly because they are printed in shades of gray without image enhancement or cartographic symbolization. Orthophotoquads are valuable as map substitutes in unmapped areas and as complements to existing line maps.

A number of county maps at scales of $1: 50,000$ or $1: 100,000$ have been prepared cooperatively with some States. The maps are multicolored, show political boundaries, a complete road network, and a variety of topographical and cultural features.

A series of 1:100,000-scale quadrangle maps will provide much of the detail shown on larger scale maps yet cover enough geographic area to be useful as base maps for county-wide and regional studies.

State base maps at scales of $1: 500,000$ and $1: 1,000,000$ are available for all States except Alaska and Hawaii which are covered by State maps at other scales. There are also shaded-relief editions for many States.

The National Park Series at various scales covers national parks, monuments, and historic sites. Many of these maps are available with shadedrelief overprinting; the topography is made to appear three-dimensional by the use of shadow effects. An example of this map treatment is shown on the right side of the front cover. 
Maps of the entire United States are available in sizes and scales ranging from letter size, $1: 16,500,000$ scale to a two-sheet wall map, $1: 2,500,000$ scale. The series includes two maps, one at 1:6,000,000 scale and one at $1: 10,000,000$ scale, that show all fifty States in their correct position and scale.

The Geological Survey is also engaged in a mapping program for Antarctica. The Antarctic maps are published at several scales, primarily $1: 250$,000 , with shaded relief.

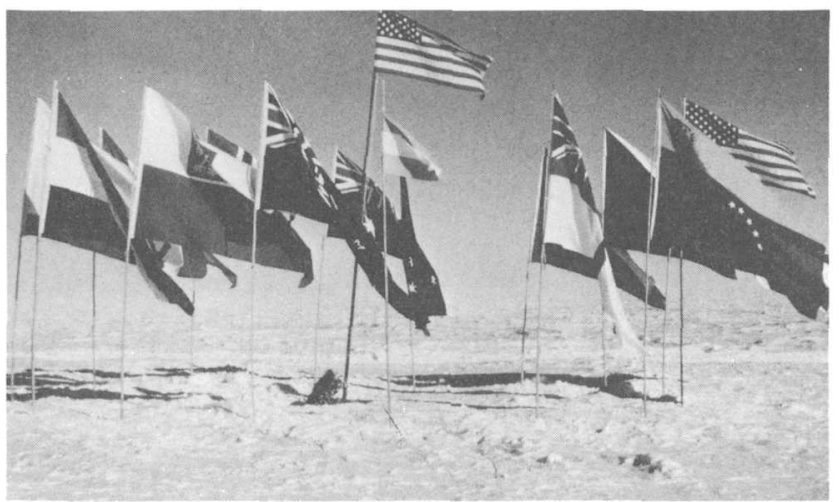

International flags at the South Pole marker

The National Atlas of the United States is a hardbound 431-page volume that describes America in a cartographic format using multicolored reference and special subject maps and an extensive gazetteer. Selected separate map sheets from the Atlas are also available.

Although most of the maps of the National Mapping Program are produced by the Geological Survey, other Federal agencies-the Defense Mapping Agency, National Ocean Survey, Tennessee Valley Authority, and the Forest Servicealso prepare topographic maps as a part of their regular activities. These maps are incorporated in the Topographic Map Series and published by the Geological Survey.

For many mapping projects, State and local agencies share the cost of mapping equally with the Federal Government. These cooperative projects expedite the mapping of areas of particular interest to the cooperating agencies and help to complete the Topographic Map Series. 


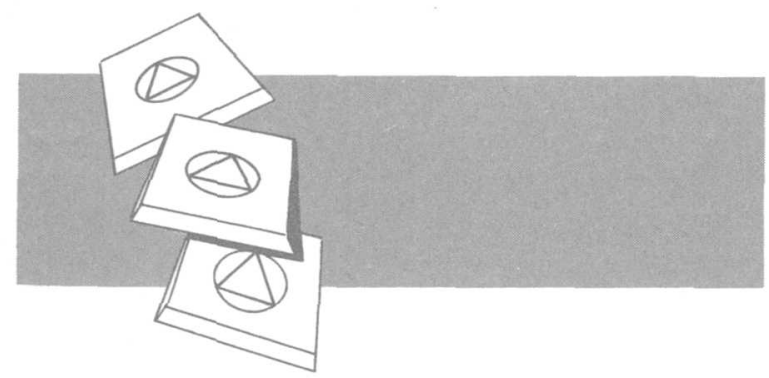

CONTROL SURVEYS are needed to present map features in correct relationship to each other and to the Earth's surface. Two kinds of control measurements are needed, horizontal and vertical. Horizontal ground control is needed to establish. and maintain correct scale, position, and orientation of the map. For this purpose, latitude and longitude of selected points within the area to be mapped are determined by field surveys. Similarly, vertical control is needed to determine the correct position of the contours which show the shape or elevation of the terrain. Thus, elevations of selected points above and below the standard zero level must also be determined in the field. Horizontal and vertical control points become the framework on which map detail is compiled. An accurate framework also permits map detail to match from one sheet to the next.

Permanent, or monumented, control points are usually marked on the ground by metal tablets 2 to 4 inches in diameter set in rock or masonry or on driven metal rods; many are shown by symbol on the maps. One mark can serve both horizontal and vertical control purposes.

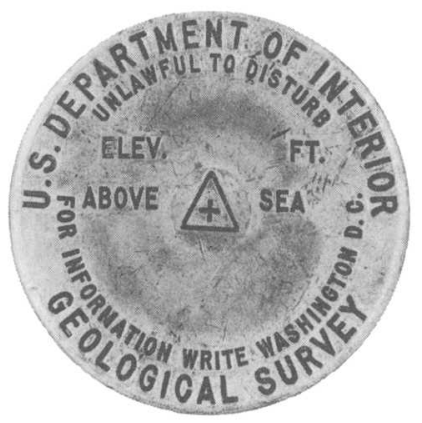


Because such data are useful for many nonmapping purposes, the results of control surveys are prepared for sale in tabulated lists. Each covers a 15-minute quadrangle. The Geological Survey and the National Ocean Survey are cooperating in publishing diagrams which show the location and order of geodetic control established by these and other Federal agencies. This information is overprinted on planimetric editions of the $1: 250,000$-scale maps.

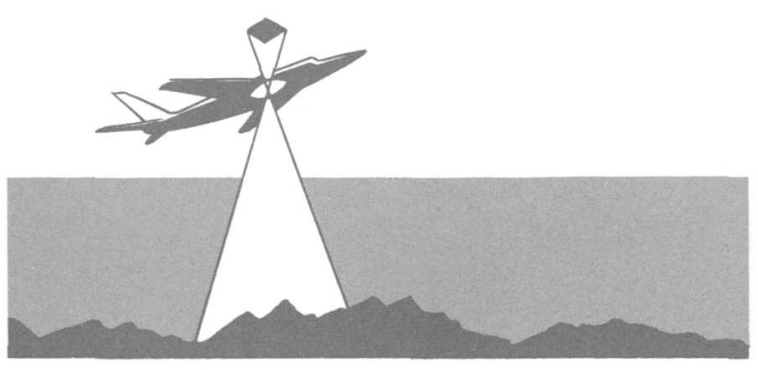

MAPPING PROCEDURES have changed considerably since the days when topographic maps were sketched by hand in the field. Today, most maps are compiled in the office by photogrammetric methods using aerial photographs and complex stereoscopic plotting instruments. Through the lens of an aerial camera the terrain is recorded from points thousands of feet above in a planned series of overlapping exposures. The resulting photographs are viewed as pairs through a plotting instrument having an optical system that causes the left eye to see one photo and the right eye to see the other. The resulting view is a three-dimensional stereomodel of the terrain from which the compiler can precisely delineate contours, drainage, woodland, and culture. If areas of the photographs are obscured by dense foliage, clouds, or heavy shadows, map features must be plotted in the field. Place names and political boundaries are verified, public land corners are located, and roads, water features, and buildings are classified by field inspection-either before or after the map manuscript is compiled from the photographs. 


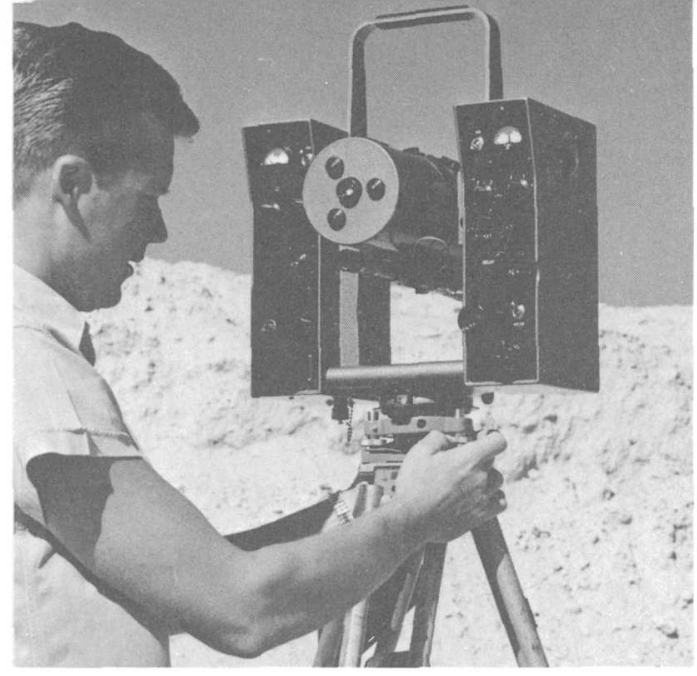

Measuring distance with an electronic instrument

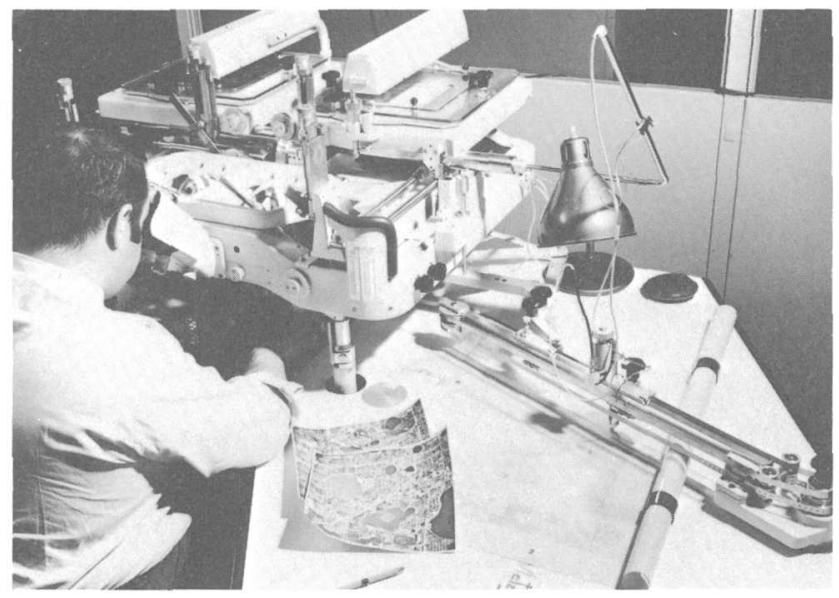

Stereocompilation

Final cartographic processing and editing are required for the preparation of plates for printing. The paper formerly used for map compilation has been replaced by a thin, paint-coated plastic. Exceptionally stable as a base, the film can be engraved or etched using special scribing tools and a light-table. As a first step from compiled manuscript to finished map, the linework is reproduced photochemically on several plastic sheets. These are used to prepare a series of scribed sheets, each containing map detail of a single color. For lithographic printing, a pressplate is made for each color by exposing the corresponding scribed sheet. Before the final run, a proof copy of the map is carefully edited for content, legibility, accuracy, and spelling. 


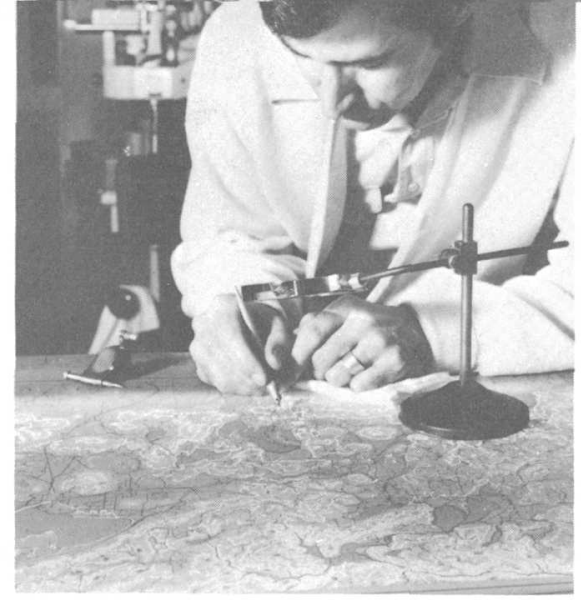

Scribing on a map manuscript

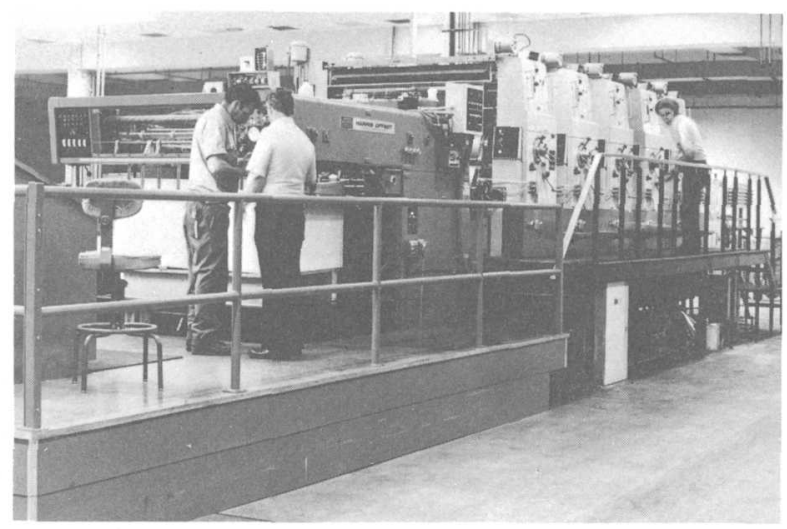

Five-color printing press

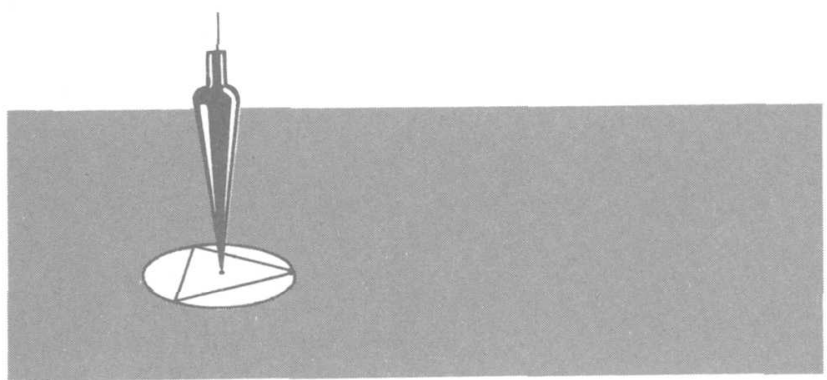

NATIONAL STANDARDS for the horizontal and vertical accuracy of topographic maps were adopted in 1941, and maps that meet these standards bear an accuracy statement in the lower margin. The standards for horizontal accuracy require that no more than 10 percent of the welldefined map points tested shall be more than $1 / 50$ 
inch $(0.5 \mathrm{~mm})$ out of correct position at publication scales of $1: 20,000$ or smaller. This tolerance corresponds to 40 feet on the ground for $1: 24,000$ scale maps and about 100 feet on the ground for 1:62,500-scale maps. The standards for vertical accuracy require that no more than 10 percent of the elevations of test points interpolated from contours shall be in error more than half the contour interval.

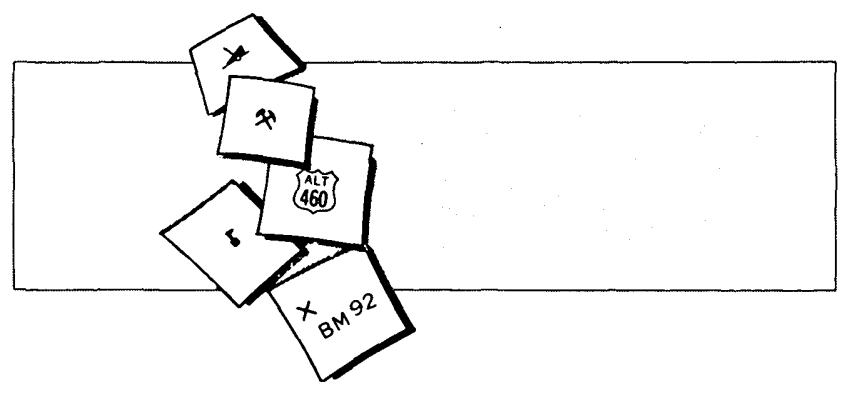

SYMBOLS are the graphic language of mapstheir shape, size, location, and color all have special significance.

On topographic maps published by the Geological Survey the colors of the symbols indicate the features they represent. Symbols for water features are blue; man-made objects-roads, railroads, buildings, transmission lines, and many others-are shown in black; and green distinguishes wooded areas from clearings. The contour lines which show the shape and elevation of the land surface-the unique characteristic of topographic maps-are brown.

Some map symbols are pictographs, resembling the objects they represent, but the brown contour lines are abstractions that have no counterpart in nature. Contour lines are an effective device for representing the vertical dimension on flat paper. Practice and imagination are needed by the map reader to visualize hills and valleys from the contour lines of a topographic map.

Some of the features depicted on a topographic map are illustrated in the accompanying bird'seye view of a river valley and the adjoining hills. 
The river flows into a bay partly enclosed by a hooked sandspit. On both sides of the valley are terraces with stream-cut gullies. The hill on the right has a smoothly eroded form and gradual slope above a wave-cut cliff, whereas the one on the left rises to a steep slope from which it falls off gently and forms an inclined tableland crossed by a few shallow gullies. An unimproved dirt road and bridge provide access to a church and two houses situated across the river from an improved light-duty road that follows the sea coast and curves up the river valley.
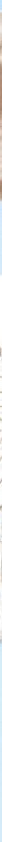

The lower illustration shows the same features represented by symbols on a topographic map. Elevations are represented by contour lines; the vertical difference between any two contours is the contour interval, or 20 feet in this illustration.

To understand the contour symbol, think of it as an imaginary line on the ground which takes any shape necessary to maintain a constant elevation above or below a reference level. If the shoreline on the map illustration is considered as 
the reference level, it is a contour representing the zero elevation. If the sea should rise and cover the land, the shoreline would trace out, in turn, each of the contour lines shown on the map. Since the vertical difference in elevation between contours in this example is 20 feet, the shoreline would coincide with a new contour each time the sea level rose 20 feet. For easier reading, index contours (every fourth or fifth contour, depending on the contour level) are emphasized by a heavier line. Supplementary contours, added to better depict areas of little relief where the basic contours fall widely spaced, are shown as dashed or dotted lines. Figures in brown shown along the index contours designate their elevations above the reference level. The elevation of any point can be read directly if it coincides with a contour, or can be interpolated if it is between contours. Map users who are concerned with quantitative measurements of terrain features can determine the data from the contours.

Maps with shaded relief are useful to those who are more interested in the general appearance and shape of the land than in exact ground elevations. The pictorial effect of contoured topographic features is enhanced by simulating the appearance of sunlight and shadows. A conventional map overprinted with shading gives the illusion of a solid, three-dimensional land surface. The maps published in shaded-relief editions are listed in the indexes to topographic maps for each State. Usually they are published only for areas of special topographic or recreational interest.

All water features are printed in blue, but are generally classified as perennial or intermittent. The perennial features contain water throughout the year (except for infrequent periods of severe drought) and are shown by solid lines; the intermittent features contain water only part of the year and are indicated by broken lines. Single lines represent streams, canals, and ditches less than 40 feet wide on 7.5-minute maps or less than 80 feet wide on 15-minute maps. Larger streams and rivers are shown to scale with double lines and a blue-tint fill. 
The blue line marking the limits of the coastal water represents approximate mean high water, always at a higher level than the zero reference for contours. Maps that include seacoasts and tidal waters sometimes show depth curves, soundings, some obstructions to navigation, and other marine details of interest, which have been extracted from nautical charts. These maps, however, are not intended for navigational purposes.

Heavily built-up areas larger than three quarters of a square mile are shown with pink-tint overprint. Streets, railroads, boundary lines, and contours are shown in the usual manner in these areas. However, the only buildings shown are landmark structures such as schools, churches, public buildings, and others that are prominent because of outstanding size, design, or historic interest. The limits of these tinted areas relate to the density of construction, not to political or legal boundaries.

Red represents or emphasizes map features such as the more important roads, route numbers, fence lines, land grants, and the lines of townships, ranges, and sections in the States subdivided by public-land surveys. Public-land lines and civil boundaries (shown in black) are mapped as accurately as possible on the basis of information obtained from documentary records and field investigations. The lines shown on the map are not intended to serve as definitive evidence of land ownership or boundary locations.

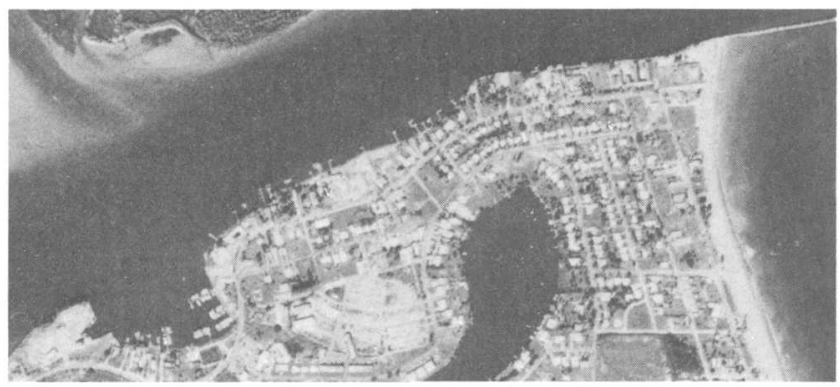

Fort Pierce area, Florida

Maps published by the Geological Survey give as complete a picture of the terrain as can be legibly produced. Standards for map content are developed through experience, and changes are 


\section{TOPOGRAPHIC MAP SYMBOLS}

Primary highway, hard surface

Secondary highway, hard surface

Light-duty road, hard or improved surface

Unimproved road

=ニニニ $=$ = = =

Trail

Railroad: sirigle track

Railroad: multiple track

Bridge

Drawbridge.

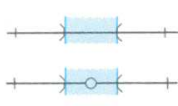

Tunnel

Footbridge

Overpass-Underpass

Power transmission line with located tower $+===: \longleftrightarrow$

Landmark line (labeled as to type)

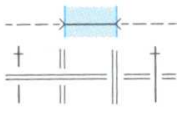

TELEPHONE

Dam with lock

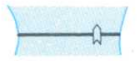

Canal with lock

Large dam

Small dam: masonry - earth

Buildings (dwelling, place of employment, etc.).

School-Church-Cemeteries

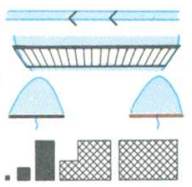

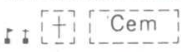

Buildings (barn, warehouse, etc.)

Tanks; oil, water, etc. (labeled only if water)

Water

Wells other than water (labeled as to type)

. Oil........ Gas

U.S. mineral or location monument - Prospect

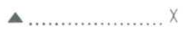

Quarry - Gravel pit

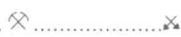

Mine shaft-Tunnel or cave entrance.

Campsite — Picnic area

v.

Located or landmark object-Windmill

Exposed wreck

Rock or coral reef.

rit?

Foreshore flat...

Rock: bare or awash

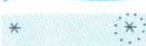

Horizontal control station

$\triangle$

Vertical control station

${ }^{B M} \times_{671} \times 672$

Road fork - Section corner with elevation

$\ 429$

Checked spot elevation

Unchecked spot elevation. 
Boundary: national

\section{State}

county, parish, municipio.

civil township, precinct, town, barrio

incorporated city, village, town, hamlet.

reservation, national or state

small park, cemetery, airport, etc.

land grant.

Township or range line, U.S. land survey.

Section line, U.S. land survey.

Township line, not U.S. land survey.

Section line, not U.S. land survey.

Fence line or field line.

Section corner: found-indicated.

Index contour.

Supplementary cont.

Cut - Fill.

Mine dump

Dune area

Sand area

Tailings.

Glacier

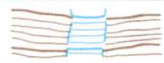

Perennial streams..

Water well_-Spring.

Rapids

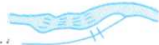

Channel

Sounding - Depth curve.

Dry lake bed

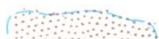

\section{Woodland}

Submerged marsh.

Orchard

Vineyard
Intermediate contour.

Depression contours.

Levee

Large wash

Tailings pond

Distorted surface..... if

Gravel beach

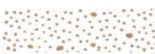

Intermittent streams

Aqueduct tunnel......... $\rightarrow=====($

Falls

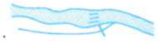

Intermittent lake

Small wash.

Marsh (swamp)

Land subject to controlled inundation

\section{Mangrove}

Scrub

Wooded marsh.

Bldg. omission area. 
adopted only after careful consideration of the needs of map users, as well as production costs and operational problems. Small but important features are exaggerated in size to make them readable. Some features are mapped because of their relative local or regional importance, such as wells and springs in the arid Western States; other features, such as windmills and fence lines, are mapped for their value as landmarks. The symbols most commonly used on topographic maps are illustrated on pages 20 and 21 .

Geographic names are an important part of a quadrangle map. Much effort is spent in establishing correct map nomenclature based primarily on current local usage. Name controversies are resolved by the U.S. Board on Geographic Names established by law to determine the choice, spelling, and application of geographic names on maps and documents published by the U.S. Government.

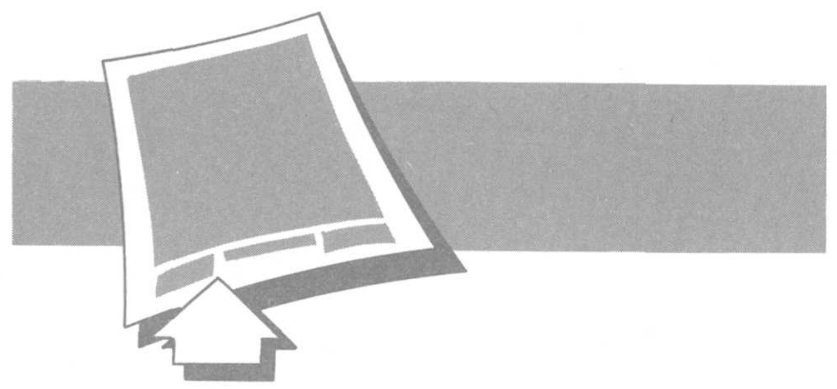

MAP MARGIN, the space outside the quadrangle border line, is used to identify and explain the map. The marginal information corresponds to the table of contents and introduction of a book, telling how the map was made, who prepared it, where it is located, when it was compiled, and (if so) when it was revised.

On a topographic map, the lines of longitude (meridians) represent true north and south with reference to the planimetric detail. Magnetic compass bearings, however, must be corrected for local variations as indicated by the declination diagram on the lower map margin. The angles of the diagram merely show the relative directions of true, magnetic, and grid north; therefore the 
angular values given in figures are to be used for corrections. Magnetic declination is continually changing (albeit very slowly), so that the value applies only for the year specified.

The current magnetic declination can be readily, and accurately determined in the locality. By orienting the map along a straight road or two distant planimetric features away from local magnetic interference, a correct magnetic north arrow can be drawn using a compass. It is possible that compass north will vary significantly across the map. There is no better way to obtain the local magnetic declination; anything else published is an approximation of this method.

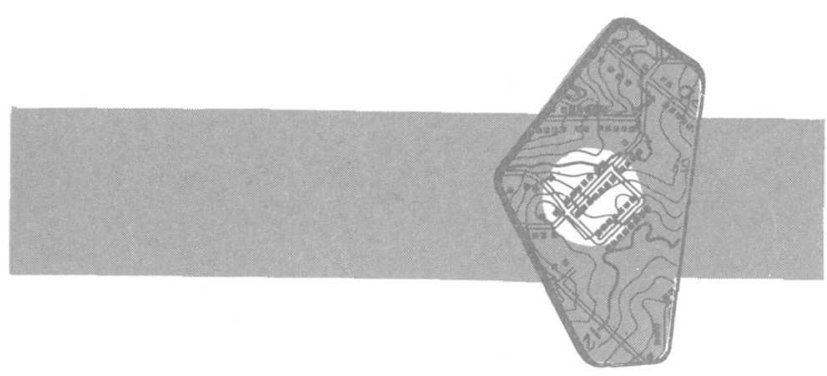

MAP REVISION is needed to keep pace with changes in man-made features such as new roads, buildings, reservoirs, and sometimes changes in the shape of the terrain. The rate and amount of change vary greatly from urban to remote areas; therefore maps are not revised at fixed intervals. The needs of map users are a first consideration in selecting maps for revision.

Revision methods vary but usually combine photogrammetric and cartographic procedures to bring the content up to date while maintaining the original accuracy of the map. The newest revision technique used by the Geological Survey consists in updating map content without field investigation. Changes interpreted from current aerial photographs are overprinted on the map in purple, so that the revised map also provides a historical comparison of development. The photorevision technique is a fast and efficient means of keeping maps as current as possible. 


\section{WHY MAPS MUST BE REVISED}

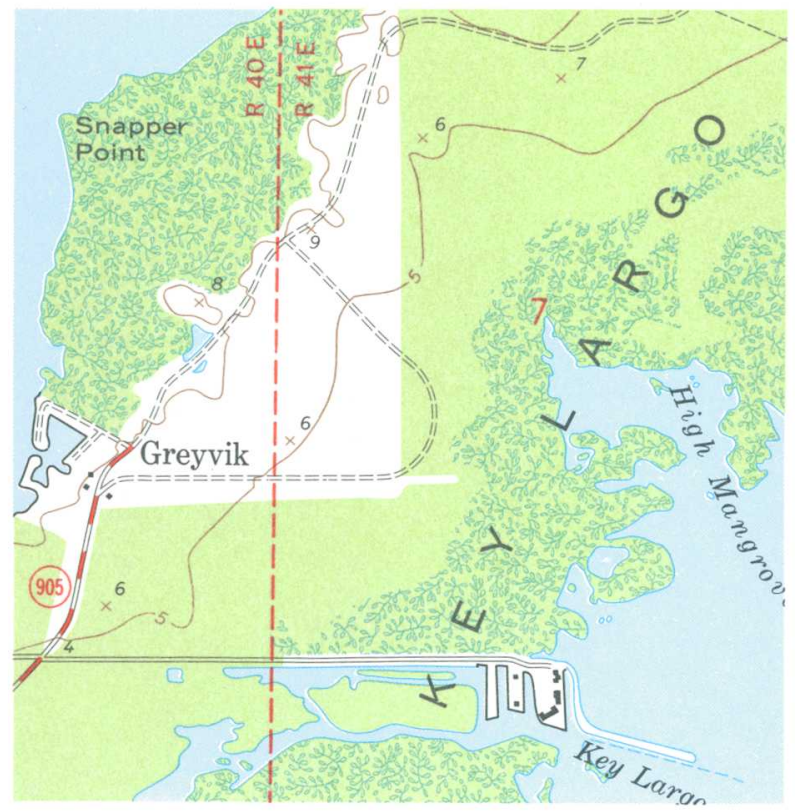

Mapped in 1949

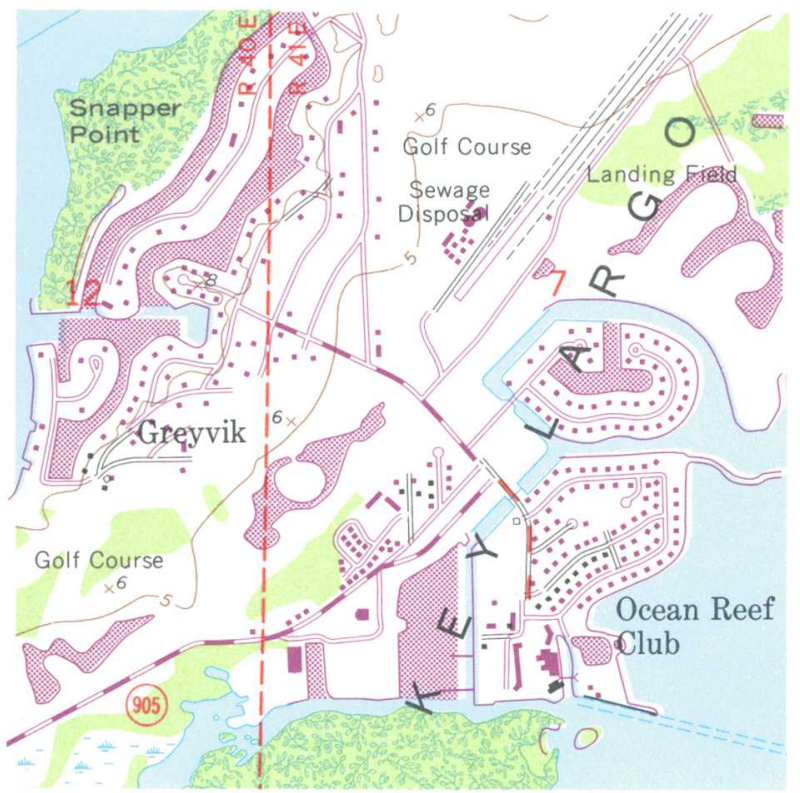

Photorevised in 1969 


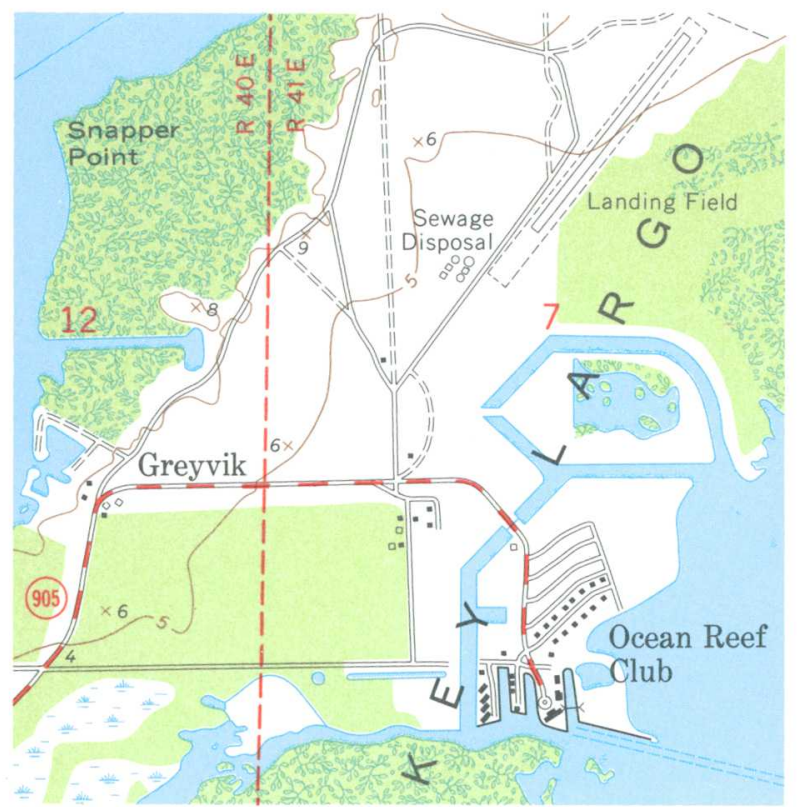

Revised in 1956

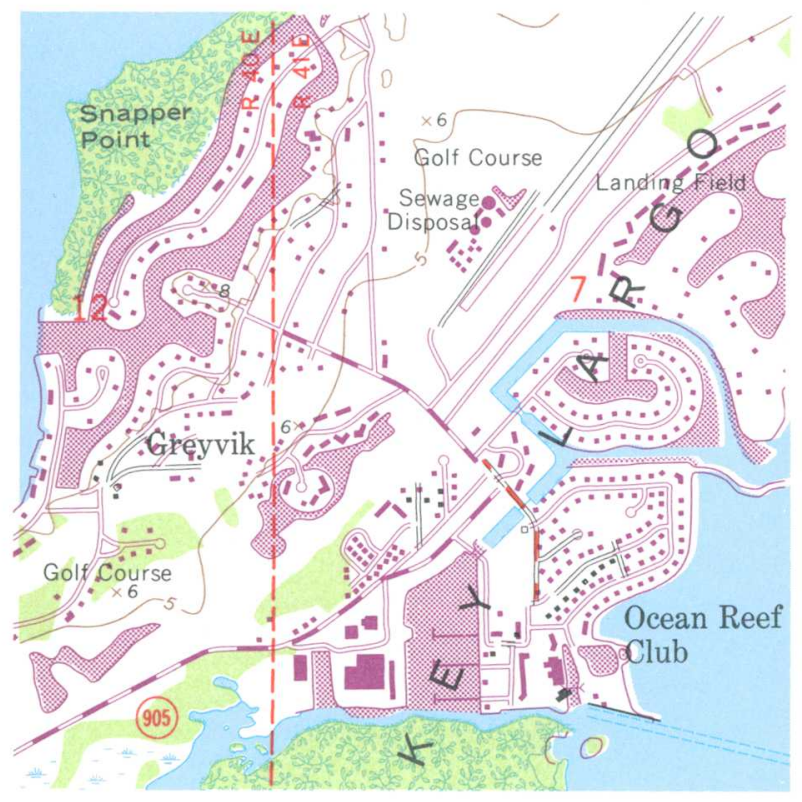

Photorevised in 1973 
INDEXES showing topographic maps published for each State of the United States and its island territories are free on request. Indexes for areas east of the Mississippi River, including Minnesota, Puerto Rico, and the Virgin Islands, may be requested from:

Branch of Distribution

U.S. Geological Survey

1200 South Eads St.

Arlington, VA 22202

Indexes for areas west of the Mississippi River, including Alaska, Hawaii, Louisiana, Guam, and American Samoa, may be requested from:

Branch of Distribution

U. S. Geological Survey

Box 25286, Federal Center

Denver, CO 80225

Residents of Alaska may request indexes directly from:

Distribution Section

U.S. Geological Survey

Federal Bldg., Box 12

101 12th Avenue

Fairbanks, AK 99701

The indexes contain lists of special maps, addresses of local map references libraries, local map dealers, and Federal map distribution centers. An order blank and detailed instructions for ordering maps are supplied with each index.

Mail orders for State maps should be sent to the appropriate Branch of Distribution or Distribution Section listed above. Payment may be made by money order or check payable to the Geological Survey.

THE NATIONAL CARTOGRAPHIC INFORMATION CENTER (NCIC) provides a national information service on maps, charts, aerial and space photographs, geodetic control, and other cartographic data for the United States. NCIC is able to inform the customer what data are available, identify what agency holds the data, and provide instructions on placing orders.

For more details contact the:

National Cartographic

Information Center

U. S. Geological Survey

507 National Center

Reston, VA 22092

Telephone: (703) 860-6045 


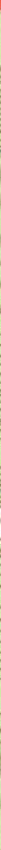

As the Nation's principal conservation agency, the Department of the Interior has responsibility for most of our nationally owned public lands and natural resources. This includes fostering the wisest use of our land and water resources, protecting our fish and wildlife, preserving the environmental and cultural values of our national parks and historical places, and providing for the enjoyment of life through outdoor recreation. The Department assesses our energy and mineral resources and works to assure that their development is in the best interests of all our people. The Department also has a major responsibility for American Indian reservation communities and for people who live in Island Territories under U.S. administration.

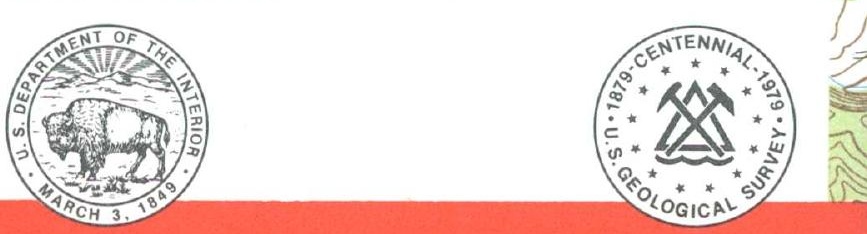

